\title{
Article \\ Experimental and Numerical Studies of Stress Distribution in an Expanding Pin Joint System
}

\author{
Soheil Salahshour *, Øyvind Karlsen and Hirpa Gelgele Lemu \\ Department of Mechanical and Structural Engineering and Materials Science, University of Stavanger, \\ N-4036 Stavanger, Norway; oyvind.karlsen@uis.no (Ø.K.); hirpa.g.lemu@uis.no (H.G.L.) \\ * Correspondence: salahshoor.soheil@gmail.com
}

\begin{abstract}
Pin joints are widely used mechanisms in different industrial machineries such as aircrafts, cranes, ships, and offshore drilling equipment providing a joint with possibility of relative rotation about one single axis. The rigidity of the joint and its service lifetime depend on the clamping force in the contact region that is provided by the applied torque. However, due to the tolerance needed for insertion of a pin in the equipment support bore, the pin is prone to relative displacement inside the bore. The amplitude of this relative displacement usually increases as time passes and since the material of the support often has lower quality grade than the pin, it leads to creation of slack in the equipment and malfunctioning of the machine. An Expanding Pin System (EPS) can be a solution to this problem where the split sleeve expands to remove the gap while the joint is torqued. Therefore, slack in the joint system disappears and $360^{\circ}$ contact area could be achieved, providing a better stress distribution and preventing the stress localization. Determining the EPS preload and the resulting contact pressure and stresses in the joint parts are important to avoid damaging to the contact surfaces of the joints and making the dismantling of the EPS difficult. Therefore, finding the amount of the required torque is a compromise between preventing slack in the EPS and prohibiting damage to the joint parts. Stress analysis in this study is performed based on the industrially recommended torque for the EPS type under study. This article reports the study conducted on the stress distribution and the magnitude of stresses exerted to the equipment support when EPS is installed on the machine. To achieve this purpose and to investigate the stress distribution in the joint, both experimental and finite element (FE) methods were used. The experimental results show how much of the applied energy to the EPS in the form of torque is spent to expand the split sleeve and test boss and also to overcome friction. The finite element analysis provides magnitude and distribution of stresses in the EPS components.
\end{abstract}

Keywords: expanding pin system joint; stress distribution; finite element analysis; split sleeve; friction effect

\section{Introduction}

A pin joint is a type of connection between two objects that provides relative rotation about a single axis. All translations as well as rotations about other axes are prevented and it is considered a single degree of freedom (DoF) system. In kinematics, a pin joint is formally called a revolute joint and when analyzing motion in two dimensions, it may also be referred to as a pivot point or a hinge. A pin joint has many applications in oil and gas, lifting, offshore, shipping and other heavy machineries in many industries. A pin joint is always susceptible to wear and tear due to slip between metal surfaces in contact, regardless of greasing time intervals. When support bores become worn, it requires restoring the holes to their original diameters and tolerances and the pivot joint has direct impact on the functioning of the machine. When the machine supports wear out, the machine will not perform properly and necessitates repair to avoid any further failures. The support bores for cylindrical pins are usually a little bit larger than the pin diameter to let the pin enter, but at the same time the diameter difference creates slack. 
The expanding pin system (EPS) shown in Figure 1 is a pivot pin assembly with a high potential for replacement of old cylindrical type of pivots. EPS is a perfect solution for slack problem in pin-support connections. In the EPS, normally both ends of the pin are tapered and a pair of expansion sleeves are fitted at both ends of the pin followed by end plates or load transfer elements. As the tightening screws or bolts are tightened, the expansion sleeves are forced over the tapered ends of the pin creating a wedge force and contact pressure between the pin and the support holes, which locks the EPS into the pivot. This system eliminates the wearing process on the contact surfaces between the pin, sleeve and support bore. The expanding pin system can be installed and retrieved easily without using forces such as by sledgehammering, hence wear and crack initiation are hindered. Additionally, it provides greater safety [1].

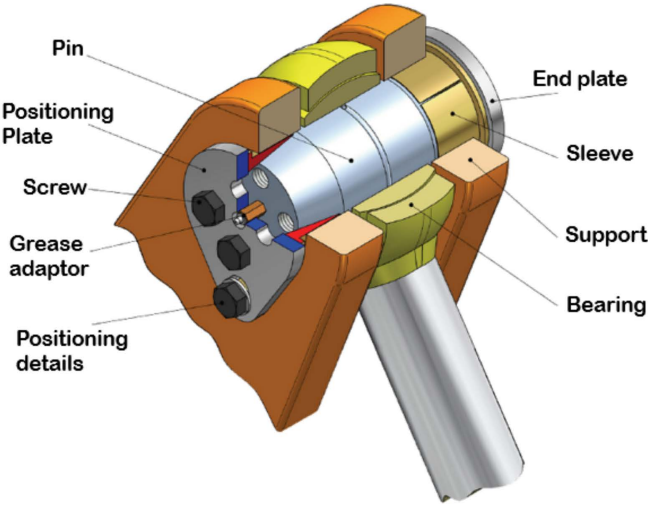

(a)
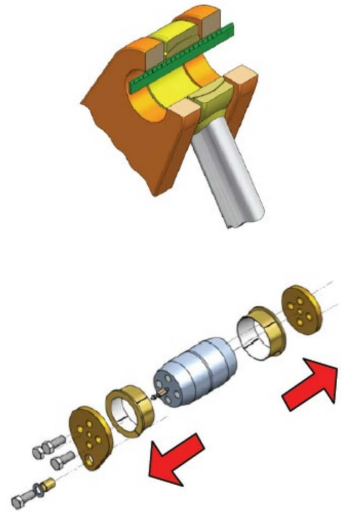

(b)

Figure 1. Illustration with section view of EPS. (a) EPS installed in a joint (b) Exploded view.

One of the main advantages of EPS is providing larger contact areas between pin and machine supports, which means reduction of stress localization induced to the supports of the machines and elimination of relative movements between contact surfaces. When torque is applied to the EPS that is locked inside the support bore, the contact area will be $360^{\circ}$ while this does not occur for standard cylindrical pins. Upon applying external loads on this locked EPS joint, the alternating pressure area becomes $180^{\circ}$ in radial pulling or pushing sequences [1], and $360^{\circ}$ in axial directions and also when unloaded.

Investigation and analysis of stress inside the support of the pin started from works of Timoshenko and Goodier [2], where solution for the stress concentration at a hole in an infinite plate loaded by a pin were obtained. Several analytical and experimental studies were also carried out by other researchers on both isotropic and orthotropic materials [3-5]. For instance, Yavari et al. [6] investigated stress around a hole in Timoshenko plate numerically considering connection design aspects such as plate geometry, clearance and friction. Though the subject of stress analysis of an expanding pin assembly has not attracted so much attention, studies on interference and shrink fitted joints are reported in the literature, which are related topics. For instance, Bozkaya and Müftü [7] investigated the mechanics of the taper interference fit analytically. They compared the analytical results with FE analysis results. It was observed that for the central $90 \%$ of the contact length, the results of the two methods are in good agreement, but they have significant differences at the beginning and the end of the contact length due to the ability of FE to find local stresses. Dongliang et al. [8] studied a conical expansion sleeve joint numerically and analyzed the magnitude of contact stresses in the joint conical surface. Yu and Yang [9] studied the torque capacity and contact stress for a new shrink disc both numerically and experimentally, which is applicable in wind turbines. Their analysis predicted the effectiveness of mechanical transmission and gave stress-strain curves to characterize the material behavior. Siemiatkowski et al. [10] investigated shrink-fitting of the marine diesel crankshaft and measured the stresses inside the crank using non-destructive method via ultrasonic measuring device. Croccolo et al. [11] provided an experimental methodology to 
determine the friction coefficient in bolted joints in order to relate the tightening torque to the preload force more precisely. Nigrelli and Pasta [12] applied 3D FE method to simulate cold expansion of a split-sleeve to determine residual stress field around an expanded hole. Their simulation highlights the effect of the split-sleeve and the plate thickness on the residual stress field. Ismonov et al. [13] performed similar 3D FE analysis to that of Nigrelli and Pasta's study [12] to predict the resulting residual stress field taking into account the effects of geometrical and material nonlinearities.

In earlier research at University of Stavanger, which is partly used as source for this study, Berkani et al. [14] conducted experimental and numerical study of the stress level in the supports. The experimental work was performed using a test boss that acted as the host support. By installing strain gauges (SGs) on four different points on the circumference of the test boss, they managed to read the strains created during tightening of screws of the assembly. Their experiment includes two EPS assemblies with $88.9 \mathrm{~mm}$ and $120 \mathrm{~mm}$ diameters. For numerical analysis, ANSYS software was used to analyze stress distributions and magnitude in steps defined for inserting preload on screws and they considered the model of test boss both with free (like their experimental test) and fixed boundary conditions. The FE results of a fixed test boss showed a more even stress distribution.

Since the sleeve is embedded between the pin and the support holes, its radial expansion was restricted leading to dissipation of part of tightening energy. A similar study was performed by Andrzejuk et al. [15] where a conical sleeve with pivot joint under axial loading was studied. In their study, they evaluated energy dissipation between cooperating surfaces of a friction pair theoretically and experimentally, and additionally they included structural friction, elastic, and frictional effects by considering the Lame's problem.

Based on the previous studies, it could be concluded that there is a need for more study and investigation on stress distributions in the equipment supports and interaction between different parts of the EPS assembly. Therefore, in this study, which is based on master thesis research conducted by the first author [16], a combination of experimental and numerical methods are used to investigate stress distribution in the joint components. The equipment support is replaced with a test boss for measuring the strains created in the equipment support while tightening the joint screws. Three different experiments are conducted to assess energy loss in the EPS, which often happens in the form of friction and the energy for expanding the sleeve. FE simulation of EPS is created in Abaqus/CAE software and its results are compared with the experimental results obtained for the test boss. Since the pin and the expansion sleeve both are embedded inside the support, acquiring strains using strain gauge is infeasible. However, the stresses and the contact pressure at the interaction surface of the pin-sleeve extracted from FE analysis are compared with theoretical formulas available in [15], even though these formulas are developed for a sleeve without any cuts. The EPS sleeve has four cuts where one of them is a complete cut-through. The comparison provides an insight into what extent these formulas are applicable for an EPS.

\section{Analysis Methods}

The study was conducted by using both experimental and numerical methods. In this section, the experimental and FE methods of analyzing the EPS joint are described.

\subsection{Experimental Setup}

To evaluate the stress distribution inside the equipment support bore of the machinery where EPS is used, a test boss was designed and manufactured for this experiment. The inner and outer diameters of the test boss are $89 \mathrm{~mm}$ and $129 \mathrm{~mm}$, respectively. The pin has a diameter of $88.9 \mathrm{~mm}$ with both ends tapered. The external hoop strains of the test boss were recorded using strain gauges installed on the outer surface of the test boss. Application of torque to the tightening screws of the system was performed stepwise. HBM strain gauges of type LY4-1-5/120 were used in this experimental study.

The test was conducted at room temperature in the range of $21.7^{\circ} \mathrm{C}$ to $23{ }^{\circ} \mathrm{C}$. Even though the temperature difference is very low and may not have any significant effect 
on the strain measurements, a compensation method was deployed to omit the effect of temperature variations. This method is known as dummy gauge. In this technique, a dummy gauge which is identical to the active one is installed on an unstrained sample of the same material as the test specimen [17]. The sample with the dummy gauge was placed in thermal contact with the test specimen, adjacent to the active gauge, as illustrated in Figure 2a. In this experiment, the dummy gauges were wired into a half-Wheatstone bridge [18] and placed close to the active gauges so that the temperature effects on the active and dummy gauges cancel each other.

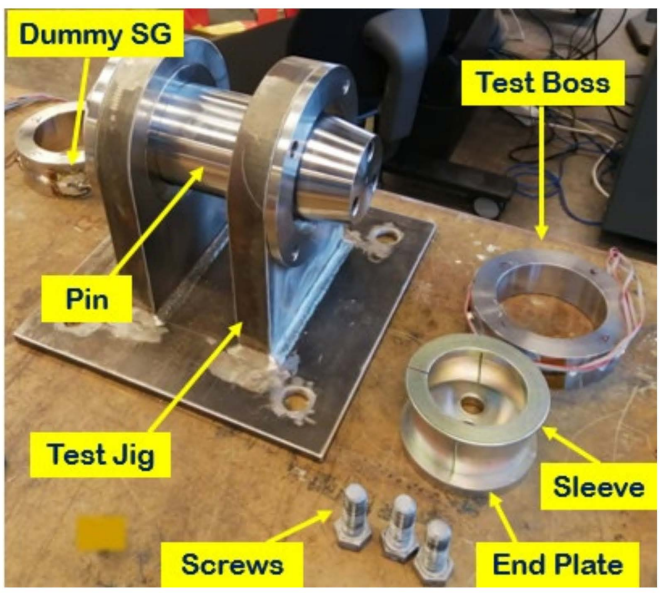

(a)

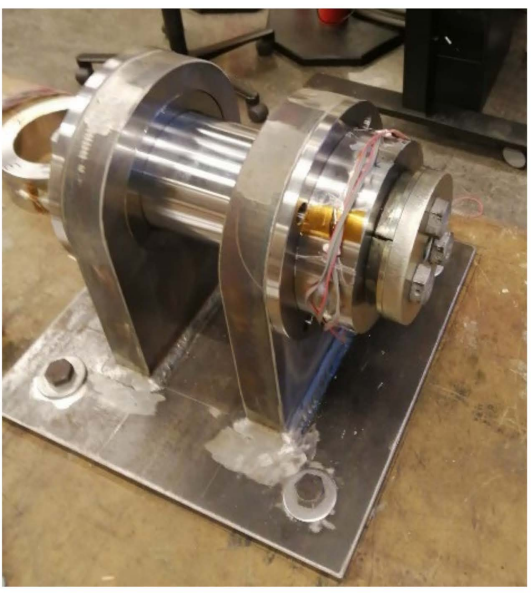

(b)

Figure 2. Experimental setup with active-dummy gauge technique. (a) Disassembled EPS joint components (b) Assembled EPS joint components.

In the test setup of this study, the half-Wheatstone bridge configuration was applied to 3 pairs of active-dummy gauges and all of them were plugged into the HBM's amplifier QuantumX.

Catman 4.5 software, which is a data acquisitioning software, was used for recording of strains generated during the tests. The software interprets the data received from QuantumX and allows visualization, analysis and storage of data during the strain measurement process. Parameters such as strain k-factor and bridge type are inputs and in addition, calibrating the gauges can be implemented. The strain output is given in (micrometer/meter) vs. time. The test procedure was implemented by rotating the test boss for $90^{\circ}$ after each test. In this way, the strains were measured for each location with angular distance of $90^{\circ}$ from each other according to standard polar coordinate.

To investigate the stress distribution of the EPS, three different test layouts were performed, namely (1) non-lubricated partly cut sleeve, (2) lubricated partly cut sleeve and (3) lubricated completely cut sleeve. The purpose of doing a test with lubricated partly cut sleeve in layout (2) was to evaluate the effect of friction, compared with the non-lubricated part, and to analyze how much of applied torque dissipates by friction. In addition, the point of interest for performing tests on lubricated completely cut sleeve in layout (3) was to analyze how much of the applied torque to the joint system is merely used to expand the sleeve elastically. In addition, in the case of test layouts (1) and (2), i.e., non-lubricated and lubricated partly cut sleeve, the effect of position of the complete cut-through is investigated by rotating the sleeve.

The test jig (shown in Figure 2) was used to resemble the equipment supports and the assembly of the pin system. The test boss was restricted to move axially during the process of applying torque which presents the real situation in practice, and this is an important purpose of conducting this experimentation.

The EPS with Ø88.9 pin system has three 8.8 quality M16 tightening screws and by tightening them, the locking mechanism of the system is triggered. The recommended torque for this pin system is $160 \mathrm{Nm}$. To provide a wider view of the joint performance, 
torques in the range between $40 \mathrm{Nm}$ and $200 \mathrm{Nm}$ were applied to the system. The yield stress of the screw material is $640 \mathrm{MPa}$ and applying $200 \mathrm{Nm}$ torque, the highest in the range, induced $311 \mathrm{MPa}$ tensile stress in the screws which is less than the yield strength of the screw material. This implies that the deformations in the screws are within the elastic region. To reduce the effect of friction force in the screws, lubricant was applied before installation. In many dry threaded fastener applications, up to $90 \%$ of the torque is consumed to overcome the bearing and the thread friction, while only $10 \%$ of the actual work is usefully transformed into tightening the screw [19]. The lubricant was applied using lubrication paste with the trade name of MOLYKOTE(R) P-74 PASTE.

\subsection{Finite Element Analysis in Abaqus/CAE}

To simulate a more realistic behavior of EPS joint applying FE analysis, using the true stress and true plastic strain relation is suggested [20]. The true stress $\left(\sigma_{\text {true }}\right)$ and the true strain $\left(\epsilon_{\text {true }}\right)$ can be determined based on material test results using the following equations [20]:

$$
\begin{gathered}
\sigma_{\text {true }}=\sigma_{\text {eng }}\left(1+\epsilon_{\text {eng }}\right) \\
\epsilon_{\text {true }}=\ln \left(1+\epsilon_{\text {eng }}\right)
\end{gathered}
$$

where $\sigma_{\text {eng }}$ and $\epsilon_{\text {eng }}$ are engineering stress and strain measured in tensile tests. True stress is the applied load divided by the actual cross-sectional area of specimen where the area changes with time while engineering stress is the applied load divided by the original cross-sectional area of specimen.

According to data from material certificates for different parts of EPS, including yield strength $\left(R_{e}\right)$, ultimate tensile strength $\left(R_{m}\right)$ and final elongation $(A 5)$, the material modeling in Abaqus was performed. The data for strain corresponding to ultimate strength was not available, however, based on stress-strain diagram available for S355 steel in the literature [21], it was assumed that the respective strain for ultimate strength is equal to one third of the strain value corresponding to the $A 5$ where the rapture for test material occurs. This assumption may contribute with some modelling error in the results. $A 5$ is permanent elongation for proportional specimens with length $L_{0}$ equal to 5 times the diameter. In this way, a linear strain hardening has been introduced for different grades of S355 steel.

Material characteristics of different parts of EPS are listed in Table 1. In Abaqus, postyielding behavior of the material can be defined in the plasticity section of material features. The plastic data define the true yield stress of the material as a function of the true plastic strain [20]. Table 2 shows, for instance, the conversion from engineering to true material properties data for sleeve. The plastic true strain is obtained by subtracting the elastic strain from the value of the total true strain as it is expressed in the following equation:

$$
\epsilon_{\text {pl.true }}=\epsilon_{\text {true }}-\epsilon_{\text {elastic }}=\epsilon_{\text {true }}-\frac{\sigma}{E}
$$

Table 1. Material characteristics of EPS parts.

\begin{tabular}{cccc}
\hline Part & $\begin{array}{c}\text { Yield Strength } \\
\boldsymbol{R}_{\boldsymbol{e}}[\mathbf{M P a}]\end{array}$ & $\begin{array}{c}\text { Ultimate Strength } \\
\boldsymbol{R}_{\boldsymbol{m}}[\mathbf{M P a}]\end{array}$ & Elongation, $\boldsymbol{A 5}$ [\%] \\
\hline End Plate & 404 & 547 & 25.6 \\
Pin & 962 & 1074 & 16.8 \\
Sleeve & 404 & 547 & 25.6 \\
Test Boss & 420 & 583 & 21.2 \\
\hline
\end{tabular}

Table 2. Sleeve stress and strain conversions.

\begin{tabular}{lccccc}
\hline & Eng. Stress & Eng. Strain & True Stress & True Strain & True Plastic Strain \\
$\boldsymbol{\epsilon}_{\text {eng }}[\mathrm{MPa}]$ & 404 & 0.0019 & 404.77 & 0.0019 & $\boldsymbol{\epsilon}_{\text {pl.true }}[-]$ \\
\hline Yield stress point, $R_{e}$ & 547 & 0.0853 & 593.66 & 0.0819 & 0 \\
Ultimate stress point, $R_{m}$ & & $4-]$ & 0.0800 \\
\hline
\end{tabular}


At small values of strain, the differences between the engineering and true strains are negligible, but the differences become significant at larger strain values. Thus, providing the proper stress-strain data to Abaqus is important especially for simulations with high strain values.

The parts are modelled as a 3D homogeneous solid, and assembly of the parts implemented according to the manner conducted in experimental set-up. The cylindrical parts have been set in place by defining coaxial and a face-to-face constraint.

A simplification was applied to the EPS joint to make the model simpler and to decrease the simulation time. This was obtained by omitting the tightening screws of the end plate and therefore equivalent axial load is defined instead of screw preload. In this way, the number of contact surfaces were decreased, and complexity of the analysis was reduced since the main focus of this FE analysis is evaluation of stresses in the contact surfaces of pin-sleeve-test boss.

The contact between EPS components was modelled based on Coulomb friction. Coulomb model characterizes the frictional behavior between two surfaces using a friction coefficient, $\mu$, and actually contacting surfaces will not slip until the shear stress equals the amount of $\mu \times p$ where $p$ is the contact pressure between the two surfaces. The friction coefficient was considered equal to 0.2 , similar to the value considered in theoretical calculations.

The quality of the mesh element determines the accuracy of the solution in a FE simulation [22]. The element selected to mesh EPS parts is C3D8R, a continuous threedimensional, eight-node linear brick, reduced integration, and hourglass controlled element. Due to the reduced integration, the locking phenomena that is a problem with some element types such as the C3D8 element did not appear [23]. A uniform mesh with $4 \mathrm{~mm}$ in size was applied to all joint components. The meshed model is shown in Figure 3a.

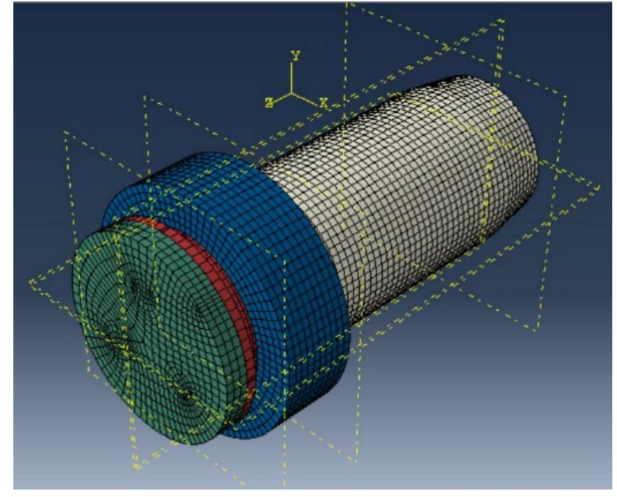

(a)

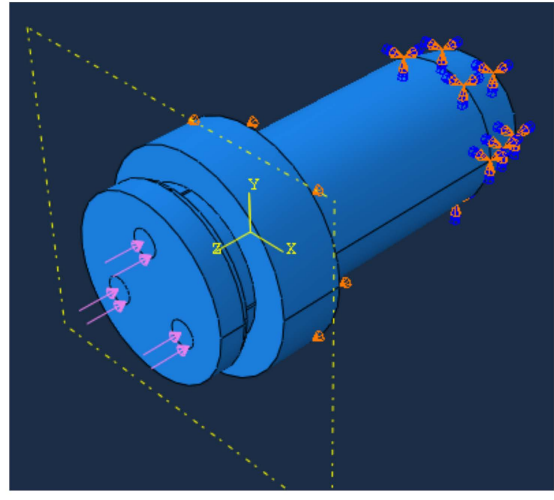

(b)

Figure 3. EPS model in Abaqus/CAE. (a) Mesh model (b) Boundary conditions.

Boundary conditions applied to FE model of EPS include clamping of the taper end of the right side of the pin and moreover preventing axial movement of the test boss. The loading of the system is modelled by inserting axial pressure to three circular partitions on the face of the end plate which resembles the axial preload of the EPS created by fastening torque (Figure $3 b$ ).

Abaqus dynamic/implicit solver was selected to conduct the simulation analysis and the quasi-static state was activated since the nature of this simulation is not completely static and during applying load to the joint system, the momentum effects cannot be ignored.

\section{Results}

In this section, the test results for the three different test layouts are provided separately. The test results provide stresses experienced by the test boss. 


\subsection{Non-Lubricated Partly Cut Sleeve}

Coefficient of friction depends upon the surface roughness, especially with the dry friction. The conical sleeve, pin and test boss used in this experiment have similar surface roughness of $3.2 \mu \mathrm{m}$. The friction coefficient for non-lubricated condition is assumed equal to 0.2 while for lubricated condition, it is ideally assumed null. The first test layout for the experimental study is the non-lubricated sleeve with three partial cut and one complete cut which resembles the real case application of the EPS. The cleanliness of the contact surfaces of all joints components is very important on locking mechanism of the assembly, because the existence of oil, grease or any other substance can have negative effect on the functioning of the mechanism and hence the measurements may lead to fault data acquisition.

As mentioned before, the strain measurements are undertaken on three points along the outer surface of the test boss. Since the test boss is a thick cylindrical shell with thickness to radius ratio greater than 0.05 , the radial and hoop stresses in inner and outer surfaces can be determined using thick-walled cylinder formulas [24]. The inner and outer radii of the test boss are " $a$ " and " $b$ ", respectively and the general radial and hoop stresses are as follows [25].

$$
\sigma_{r}=\left(1-\frac{a^{2}}{r^{2}}\right) C_{1}+\frac{C_{2}}{r^{2}}, \sigma_{\theta}=\left(1+\frac{a^{2}}{r^{2}}\right) C_{1}-\frac{C_{2}}{r^{2}}
$$

The constants $C_{1}$ and $C_{2}$ can be determined based on the boundary conditions. The test boss was subjected to a radial stress of $\sigma_{r}=-p$ (the radial pressure) at its inner surface, $r=a$, and since there is no external pressure acting on its outer surface i.e., radial stress $\sigma_{r}=0$ at $r=b$ which simplifies Equation (4) to the following form.

$$
\sigma_{r}=\frac{p a^{2}}{b^{2}-a^{2}}\left(1-\frac{b^{2}}{r^{2}}\right), \sigma_{\theta}=\frac{p a^{2}}{b^{2}-a^{2}}\left(1+\frac{b^{2}}{r^{2}}\right)
$$

The test boss does not have any movement in axial (z) direction. The outer surface of the test boss experiences no force, but its inner surface is exposed to friction force created by outer surface of the split sleeve. Overall equilibrium of forces in the axial direction requires the following condition:

$$
\int_{a}^{b} \sigma_{z} 2 \pi r d r=\mu N
$$

In Equation (6), $N$ is the radial force created by expansion of the sleeve and it can be calculated by considering internal pressure multiplied by the internal surface area of the test boss as

$$
N=\sigma_{r, \text { int }} A=\sigma_{r, \text { int }}(2 \pi a L)
$$

where $\sigma_{r, \text { int }}$ is the internal radial stress and $L$ is the length of the test boss. Therefore, the axial stress on the inner surface of the test boss is obtained as

$$
\sigma_{z, \text { int }}=\frac{2 a L \mu}{b^{2}-a^{2}} \sigma_{r, \text { int }}
$$

By measuring the hoop strain on the outer surface of the test boss and using Equation (9), stress components including radial, hoop and axial stresses can be easily determined.

$\epsilon_{r}=\frac{1}{E}\left[\sigma_{r}-v\left(\sigma_{\theta}+\sigma_{z}\right)\right], \epsilon_{\theta}=\frac{1}{E}\left[\sigma_{\theta}-v\left(\sigma_{r}+\sigma_{z}\right)\right], \epsilon_{z}=\frac{1}{E}\left[\sigma_{z}-v\left(\sigma_{r}+\sigma_{\theta}\right)\right]=$ constant

where $E$ and $v$ denote the modulus of elasticity and Poisson's ratio of the test boss, respectively.

The strain measurements for one of the tests are provided in Figure 4a as an example. The positions of the strain gauges are changed with respect to sleeve cut-through by rotating the test boss $90^{\circ}$ after each test. The start position of strain gauges and the four sleeve cuts are demonstrated in Figure $4 \mathrm{~b}$, and the strain gauges are all placed adjacent to the sleeve cuts. 


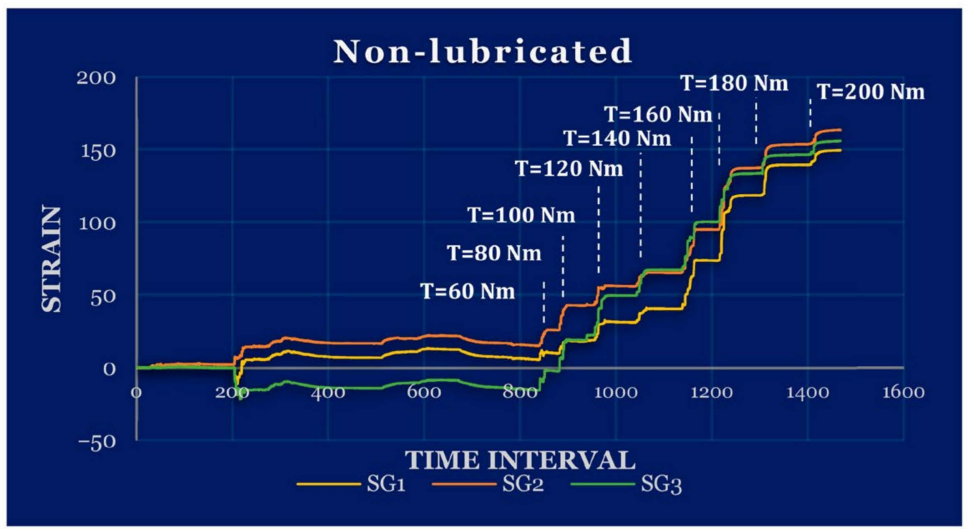

(a)

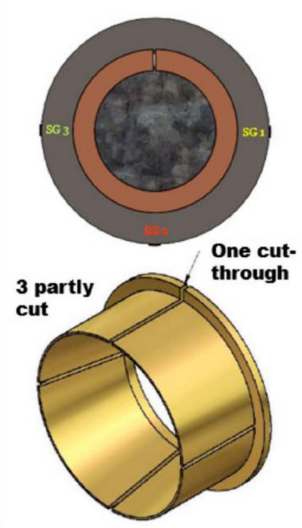

(b)

Figure 4. Non-lubricated partly cut sleeve with cut-through at top and strain gauges at $0, \pi$ and $3 \pi / 2$. (a) Recorded strains, (b) pin-sleeve-test boss.

Based on the measured strains for the non-lubricated layout and obtaining the average values, the internal and external radial and hoop stresses were calculated using Equations (5) and (9). Images (a-c) in Figure 5 show the position of the strain gauges and calculated stress values at those spots. Image (d) in the same figure shows the average stresses. It is worth mentioning that external radial stress in the test boss is zero. The stress distribution inside the test boss is not uniform, and these stresses are considered as contact pressure [26]. One of the main reasons for this uneven stress distribution is the friction. The compressive force among the contact surfaces of the conical sleeve, boss and pin creates friction force which prevents the relative slippage. In addition, the regions of the test boss at the complete cut-through experience higher stress level than the partly cuts, and the partly cuts give lower stress level than the areas between the cuts. Hence, another reason for non-uniform stress distribution is due to the cuts where the sleeve expands more in these regions and as a result varying stress levels are induced into the test boss.
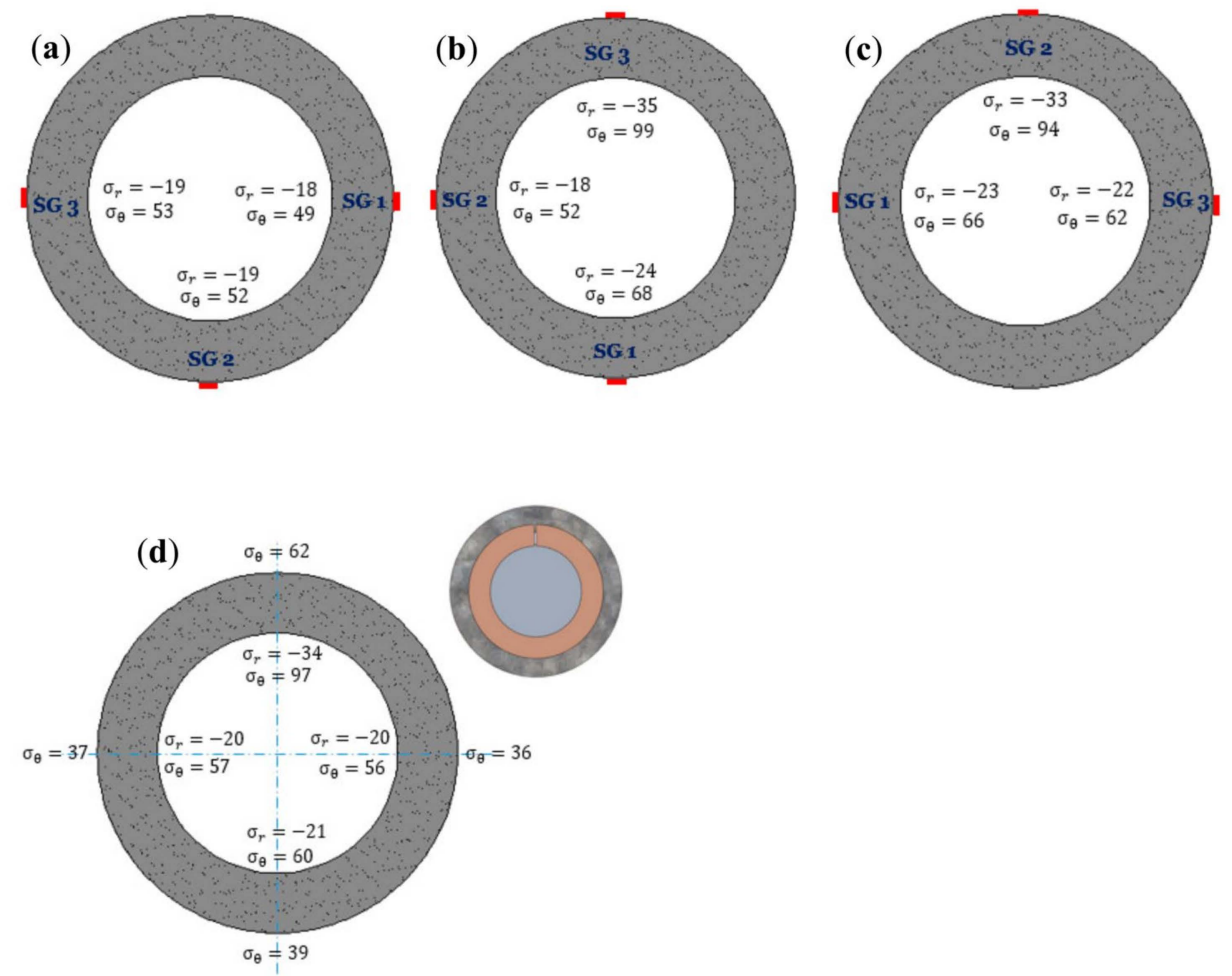

Figure 5. Non-lubricated sleeve with sleeve complete cut-through at $\pi / 2$ (stresses in MPa). (a) Test 1 (b) Test 2 (c) Test 3 (d) Average value of the three tests. 


\subsection{Lubricated Partly Cut Sleeve}

For evaluation of the effect of friction between contact surfaces of sleeve-pin-test boss, lubrication was applied to the sleeve. In this test layout, both the inner and the outer surfaces of the conical sleeve were lubricated. The purpose of these tests is to investigate how much of the applied torque dissipates in the form of hysteresis deformation along contact surfaces of the sleeve.

In practice, it is recommended to use a rubber or plastic hammer and tap all around the end plate after applying a definite amount of torque and then resume tightening. The purpose of this task is to release accumulated stresses due to existence of the static friction and to provide a better stress distribution. This step had to be skipped while tightening the screws in non-lubricated test layout, because this could affect the connectivity and accuracy of the strain gauges and lead to their damage. However, this task was implemented for lubricated test layout since lubrication decreases the level of static friction and by gently tapping on the end plate, unwanted accumulated stresses are relieved.

In this test layout, again the position of the cut-through is at $\pi / 2$. The strain graphs show that the amount of stress inside the test boss has increased significantly, compared to non-lubricated condition. The stress distribution in lubricated condition is not uniform and it is, to some extent, similar to non-lubricated condition. By comparing the change of stresses with non-lubricated condition, it is concluded that generally the stresses distribute more uniformly as friction decreases. This fact is observed in another research related to loading of a cylinder, for instance in the article of Al-Chalabi, et al. [27].

Elastic hysteresis is defined as the difference between the strain energy required to generate a definite stress in a material, and the material's elastic energy at that stress [28]. This energy is dissipated through internal friction or heat inside material during loading and unloading. Basically, hard metals do not show elastic hysteresis under a moderate loading [29], but the magnitude of stresses inside the test boss in lubricated test series is noticeable and makes this phenomenon to happen.

In order to better evaluate the effect of the sleeve cut-through, a series of tests have been carried out by placing it at different locations. In these series of the tests, the test boss is fixed and just the sleeve is rotated. The sleeve cut-through was placed at three different positions, $\pi / 4,5 \pi / 4$ and $7 \pi / 4$, respectively, shown in Table 3 , while keeping the test boss strain gauges at $\pi / 2, \pi$ and $3 \pi / 2$. This gives a relative angular distance of $\pi / 4$ between each strain gauge and its closest sleeve cut.

Table 3. Hoop stress [MPa] based on location of cut-through inside the test boss.

\begin{tabular}{|c|c|c|c|c|c|}
\hline \multirow[b]{3}{*}{ 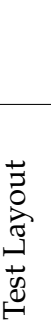 } & & \multicolumn{4}{|c|}{ Position of Complete Cut-Trough } \\
\hline & & $\pi / 2$ & $5 \pi / 4$ & $7 \pi / 4$ & $\pi / 4$ \\
\hline & $\begin{array}{l}\text { Strain Gauge Nr. } \\
\text { (Locations) }\end{array}$ & & & & \\
\hline \multirow{4}{*}{ 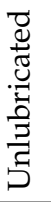 } & No SG (0) & 56 & - & - & - \\
\hline & $\operatorname{SG} 3(\pi / 2)$ & 97 & 107 & 102 & 100 \\
\hline & SG $2(\pi)$ & 57 & 85 & 104 & 79 \\
\hline & SG $1(3 \pi / 2)$ & 60 & 88 & 76 & 93 \\
\hline \multirow{4}{*}{ 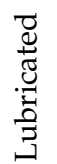 } & No SG (0) & 150 & - & - & - \\
\hline & $\operatorname{SG} 3(\pi / 2)$ & 210 & 236 & 212 & 237 \\
\hline & $\operatorname{SG} 2(\pi)$ & 188 & 216 & 209 & 220 \\
\hline & SG $1(3 \pi / 2)$ & 165 & 203 & 181 & 230 \\
\hline
\end{tabular}


The hoop stress values measured on the boss at the four cuts are compared to the corresponding values measured at location with $\pm \pi / 4$ angular distance, for both dry and lubricated sleeves. For the unlubricated case, the measurements on the boss at the cuts, which are provided in Figure 6, show a higher value, $97 \mathrm{MPa}$, for the complete cut at $\pi / 2$ compared to the opposite partly cut $3 \pi / 2$ and neighbor cuts at $\pi$ and $2 \pi$, with values equal to $60 \mathrm{MPa}, 57 \mathrm{MPa}$ and $56 \mathrm{MPa}$, respectively. This gives $68 \%$ higher stress at the complete cut, compared to the average of the three partly cuts. For the lubricated case, the corresponding measured values are $210 \mathrm{MPa}, 165 \mathrm{MPa}, 188 \mathrm{MPa}$ and $150 \mathrm{MPa}$, respectively, which gives $25 \%$ higher stress level for the complete cut, compared with the average value of the other three.

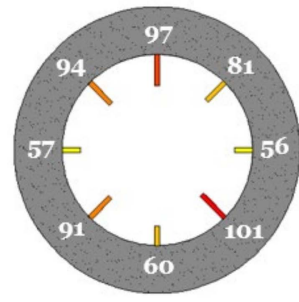

(a)

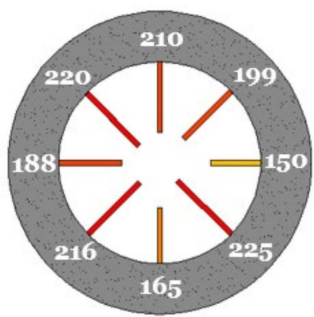

(b)

Figure 6. Hoop stresses (MPa) along inner surface of test boss. (a) Non-lubricated (b) Lubricated.

Measurements taken at positions $\pm \Delta \pi / 4$ are compared to the cut positions, and these measurements indicate changes in the stress level compared to the measurements at the cuts. The stress level close $( \pm \Delta \pi / 4)$ to the complete cut at $\pi / 2$ shows reductions from $97 \mathrm{MPa}$ to $94 \mathrm{MPa}$, and $81 \mathrm{MPa}$, respectively. The corresponding values for the opposite partly cut at $3 \pi / 2$ show an increase from $60 \mathrm{MPa}$ to $101 \mathrm{MPa}$, and $91 \mathrm{MPa}$, respectively. All values for both non-lubricated and lubricated partly cut cases are shown in Figure 6, which resembles a kind of stress distribution in the test boss.

In this test layout, the regions around the location of the sleeve cut-through experience higher stresses than other regions, which is similar to non-lubricated condition. By comparing the strains and stresses of the lubricated condition with the non-lubricated, it is found out that both radial and hoop stresses at positions of $0, \pi / 4, \pi / 2,3 \pi / 4, \pi$, $5 \pi / 4,3 \pi / 2$ and $7 \pi / 4$ are increased with ratios of $2.68,2.46,2.16,2.34,3.30,2.37,2.75$ and 2.23 times, respectively. The average of stresses in the lubricated condition is 2.54 times greater compared with the non-lubricated condition.

\subsection{Lubricated Completely Cut Sleeve}

Another test layout investigated in this experiment was lubricated completely cut sleeve. In clamping mechanism of the EPS, a part of the applied torque is used to deform the sleeve in elastic range. In the EPS, the sleeve slits make the expansion easier, but still a part of the applied torque is used to deform the sleeve. Thus, by cutting the sleeve into four separate parts, the dissipation of energy related to elastic deformation of sleeve would be omitted. The aim of these tests is to evaluate how much of torque is spent for the elastic deformation of sleeve. The sleeve is cut into four identical parts. The results of these series of tests are exhibited in Figure 7. The strains and stresses are increased significantly in comparison with previous non-lubricated and lubricated sleeve test layouts, and it is obvious that the stress distribution is to a great extent uniform along the whole inner surface of the test boss. It is concluded that radial and hoop stresses in the inner surface of the test boss at positions of $0, \pi / 4, \pi / 2,3 \pi / 4, \pi, 5 \pi / 4,3 \pi / 2$ and $7 \pi / 4$ are increased with ratios of $4.64,3.23,2.70,2.78,4.68,2.88,4.37$ and 2.59 times, respectively, compared with the non-lubricated partly cut condition. The average ratio is 3.48 . 


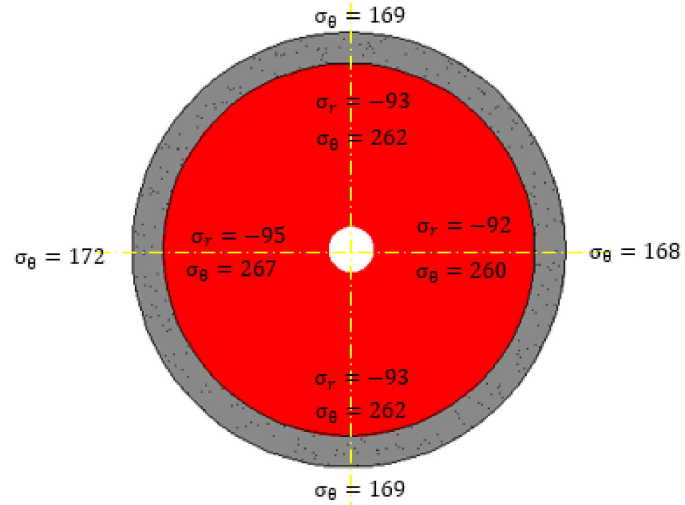

Figure 7. Distribution of hoop and radial stress for lubricated completely cut sleeve.

By making a comparison between unlubricated partly cut sleeve and lubricated completely cut sleeve test results, it is revealed that $71.3 \%$ of the total applied energy is dissipated which is actually used to deform the sleeve in elastic region of material and to overcome the friction force, i.e., elastic hysteresis. The rest of the applied energy to the EPS which is $28.7 \%$ is spent to expand the test boss elastically.

On the other hand, by comparing the test results of the unlubricated partly cut sleeve with the lubricated cut sleeve, it is found out that $60.6 \%$ of the dissipated energy is dedicated to overcoming the friction, i.e., around $43.2 \%$ of the total applied energy to the EPS is spent in the form of friction. The share of elastic expansion of the sleeve from dissipated energy is $39.4 \%$ which means a share of $28.1 \%$ of the total applied energy to the EPS, and this amount of energy remains in the clamped system in the form of residual contact pressure and disappears when the system is unlocked.

Surface roughness of the joint components is an important parameter, and it must receive special attention. The conical sleeve, pin and test boss used in this experiment have similar surface roughness of $3.2 \mu \mathrm{mRa}$ according to ISO 2768 standard.

The characteristic of hoop stress inside the test boss is tensile while radial and axial stresses are compressive. For further analysis of the test boss stress distribution through different test layouts and to find out whether it has experienced yielding or not, maximum shear stress (MSS) theory based on Tresca stress and distortion energy (DE) theory based on von Mises stress are evaluated [30]. The respective maximum Tresca and von Mises stresses are calculated for each condition based on the highest values of stresses registered during measurements. Based on the obtained results, the maximum stress has occurred on the inner surface of the test boss. For a general state of stress with principal stresses ordered as $\sigma_{1}>\sigma_{2}>\sigma_{3}$, the maximum shear stress is $\tau_{\max }=\left(\sigma_{1}-\sigma_{3}\right) / 2$. Thus, the MSS is violated, or yielding happens when the following condition dominates

$$
\tau_{\max }=\frac{\sigma_{1}-\sigma_{3}}{2} \geq \frac{R_{e}}{2}
$$

Equation (10) gives the maximum shear stress and compares it with yield stress to evaluate the failure condition of the materials. Based on the stress state in the test boss which is $\sigma_{\theta, \text { int }}>\sigma_{z, \text { int }}>\sigma_{r, \text { int }}$, then the MSS is determined by:

$$
\tau_{\max }=\frac{\sigma_{\theta, \text { int }}-\sigma_{r, \text { int }}}{2}
$$

where $2 \tau_{\max }$ corresponds to the Tresca stress criteria. The von Mises criteria, which is derived from strain energy of the elements of a part, takes the following form for a threedimensional stress state:

$$
\sigma_{\text {von Mises }}=\left[\frac{\left(\sigma_{1}-\sigma_{2}\right)^{2}+\left(\sigma_{2}-\sigma_{3}\right)^{2}+\left(\sigma_{3}-\sigma_{1}\right)^{2}}{2}\right]^{1 / 2}
$$

Therefore, the von Mises stress for the test boss is calculated similar to the above equation as follows: 


$$
\sigma_{\text {von Mises }}=\left[\frac{\left(\sigma_{\theta, \text { int }}-\sigma_{z, \text { int }}\right)^{2}+\left(\sigma_{z, \text { int }}-\sigma_{r, \text { int }}\right)^{2}+\left(\sigma_{r, \text { int }}-\sigma_{\theta, \text { int }}\right)^{2}}{2}\right]{ }^{1 / 2}
$$

It is worth mentioning that $\sigma_{z, \text { int }}$ which is given in Equation (4) can be calculated based on the geometry of the test boss for inner diameter $a=44.5 \mathrm{~mm}$ and outer diameter $b=64.5 \mathrm{~mm}$ and also assuming a friction coefficient of $\mu=0.2$, which yields $\sigma_{z, \text { int }}=0.31 \sigma_{r, \text { int }}$. Tresca and von Mises values are given in Table 4 . It can be seen from the combined stresses that in lubricated partly cut sleeve, the Tresca and von Mises stresses have increased with a factor of 2.22 and 2.23, respectively, compared to the non-lubricated partly cut sleeve. For the lubricated completely cut sleeve the corresponding values are 2.64 and 2.58 , respectively.

Table 4. Evaluation of failure (yield criteria) based on measured stresses.

\begin{tabular}{lccc}
\hline \multicolumn{1}{c}{ Test Layout } & Tresca Stress [MPa] & von Mises Stress [MPa] & Yield Strength of Test Boss [MPa] \\
\hline Non-lubricated Partly Cut Sleeve & 137 & 126 & 420 \\
Lubricated Partly Cut Sleeve & 304 & 281 & 420 \\
Lubricated Completely Cut Sleeve & 362 & 325 & 420 \\
\hline
\end{tabular}

According to the calculated values for non-lubricated sleeve which resembles the application of the EPS in practice, both Tresca and von Mises stresses are much lower than the failure limits, but for lubricated completely cut sleeve, von Mises and Tresca stresses reach $77 \%$ and $86 \%$ of the material yield strength. Tresca criteria is a more conservative than von Mises criteria.

\section{Comparison of the Results and Discussion}

The FE results obtained from Abaqus simulation will be compared with experimental results of the test boss measured from non-lubricated partly cut sleeve test layout. Since there is no experimental result for the pin and the expansion sleeve, the FE results of these parts will be compared with results of the theoretical formulas of Andrzejuk et al. [15]. Here, the comparison is performed separately for each EPS part including sleeve, pin and test boss.

\subsection{Partly Cut Sleeve}

The sleeve plays an important role in any EPS joint, because its expansion leads to creation of the clamping force. The level of von Mises stress (shown in Figure 8a) obtained from FE method is in the elastic region in different parts of the sleeve. The maximum von Mises value is $338 \mathrm{MPa}$ which occurred in the collar edge near the contact surface of end plate and sleeve. The characteristic of this stress is tension which is related to expansion of the sleeve. As it was expected, the back side of the sleeve collar has experienced a low level of stress since it does not have any contact with other parts and the stress of this region is resulted from Poisson's effect. Tresca stress distribution is similar to von Mises stress distribution, and it points out the maximum stress at the same region as von Mises criteria with magnitude of $384 \mathrm{MPa}$, which is around $14 \%$ higher than maximum von Mises stress.

Figure 8a shows that three regions in the sleeve experience higher stresses. One of these regions is at the complete cut-through. The other two regions are the regions between the cuts. One of the reasons for this matter is related to freedom of sleeve to deform at cuts and slip along the pin circumference which results in accumulation of stress in surrounding regions.

The corresponding radial stress for the sleeve in FE simulation is S11 (the first stress component, $\sigma_{1}$ ) when it is in horizontal plane, because other planes will add stress components that require further calculation to find the radial stress. This is valid as if the effects of shear stresses are ignored. Therefore, a path is defined in the horizontal plane across the tapered length of the sleeve equal to the contact length. This path is shown in Figure 8b. S11 in xz-plane gives the radial stress in the test boss at 0 and $\pi$, while S22 in yz-plane gives the 
radial stress at $\pi / 2$ and $3 \pi / 2$. It is along one of the sleeve slits (it could also be defined on the other side due to symmetry). The radial stress is obtained from S11 value in xz-plane on the defined path, shown in Figure 9a. It is compared with the result of Andrzejuk et al. [15]. Figure $9 \mathrm{~b}$ shows the contact length between the sleeve and pin which is approximately $35 \mathrm{~mm}$.

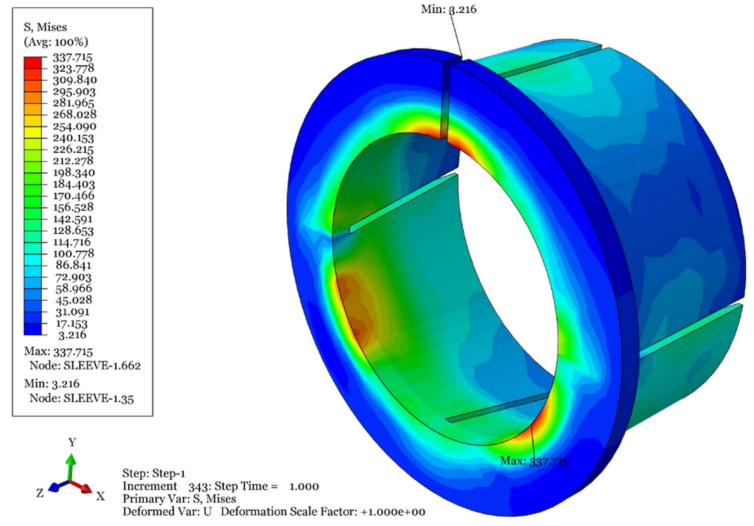

(a)

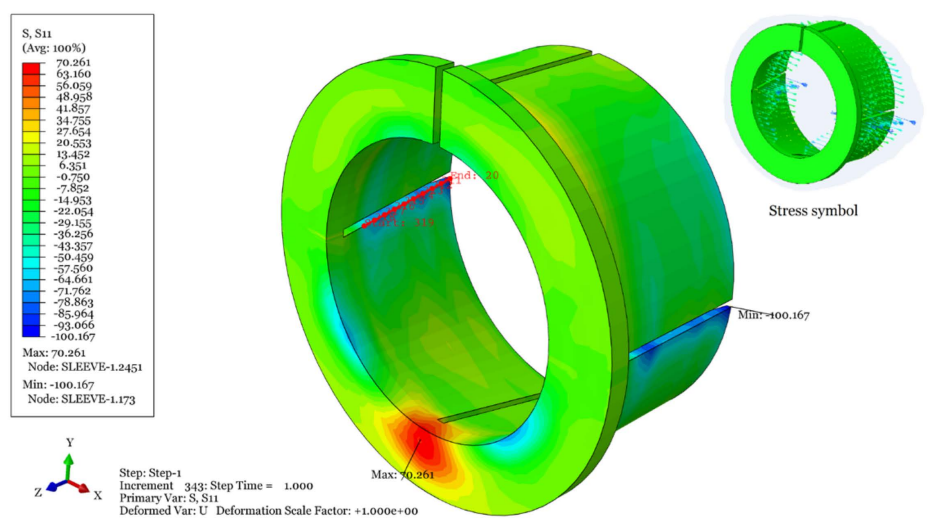

(b)

Figure 8. Stresses in sleeve resulted from $200 \mathrm{Nm}$ torque. (a) von Mises stress distribution in sleeve (b) S11 (x-dir) stress distribution in sleeve.

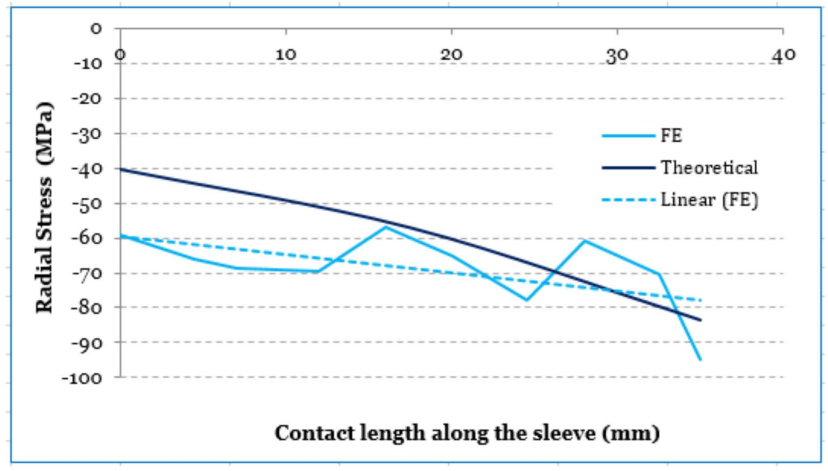

(a)

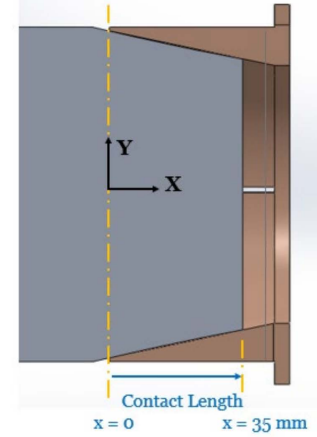

(b)

Figure 9. Sleeve radial stress along contact length. (a) Comparison of sleeve radial stress; (b) illustration of contact length.

Figure 9a shows that both theoretical and FE results predict an increase in the magnitude of radial stress as it moves from the edge of the sleeve towards its collar which is equivalent to a move from approximately beginning of pin taper towards its end. However, FE curve has some dramatic jumps which could be related to inaccuracy of FE calculations on the integration points due to mesh size. The dash line in the figure is a linear trend line for FE curve which highlights the stress increase at the end of the pin. Furthermore, it could be expressed that the prediction of formula in Andrzejuk et al. [15] for maximum radial stress is in good agreement with FE results even though it is for a sleeve without any cuts or slits.

\subsection{Pin}

Similar to the case indicated for sleeve, S11 stress in Abaqus which is the stress component in $\mathrm{x}$-direction resembles pin radial stress at xz-plane. Distribution of S11 and a path parallel to the one used for presenting radial stress for sleeve are shown in Figure 10. Variations of radial stress along the corresponding path for both the theoretical method of Andrzejuk et al. [15] and the FE results are shown in Figure 11a. It is observed that FE and theoretical results are in good agreement with each other. In different regions along the contact length discrepancies exist between the two curves. FE method calculates the stress 
values for each element and since the sleeve has four slits which one of them is a complete cut, the induced pressure of sleeve to pin is not symmetric and it is actually non-uniform. Therefore, existence of non-uniformity in radial stress of the pin is not strange. FE method shows this matter and local differences are visible in the FE curve. Both FE and theoretical methods show increase in the magnitude of radial stress along the contact length.

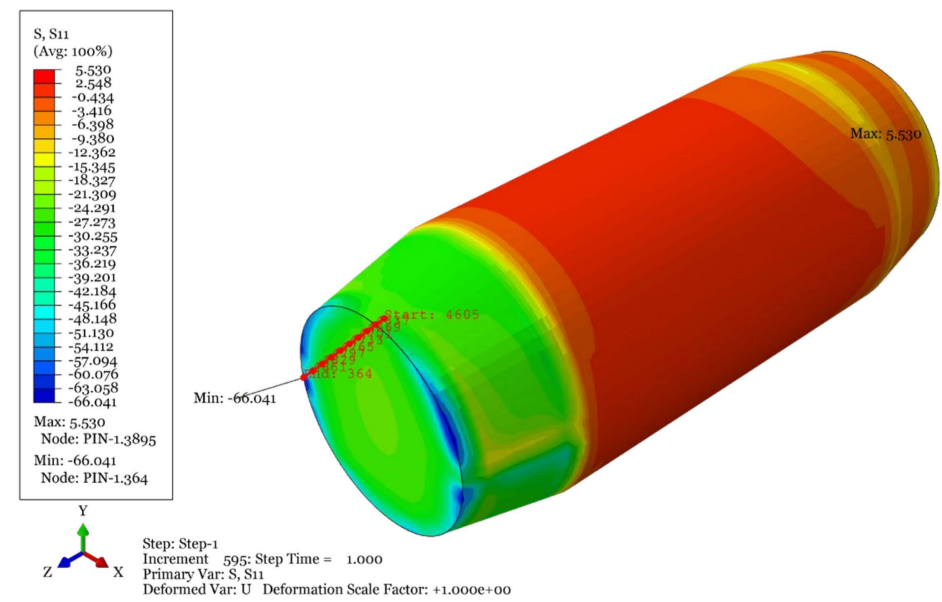

Figure 10. S11 stress distribution in pin resulted from $200 \mathrm{Nm}$ torque.

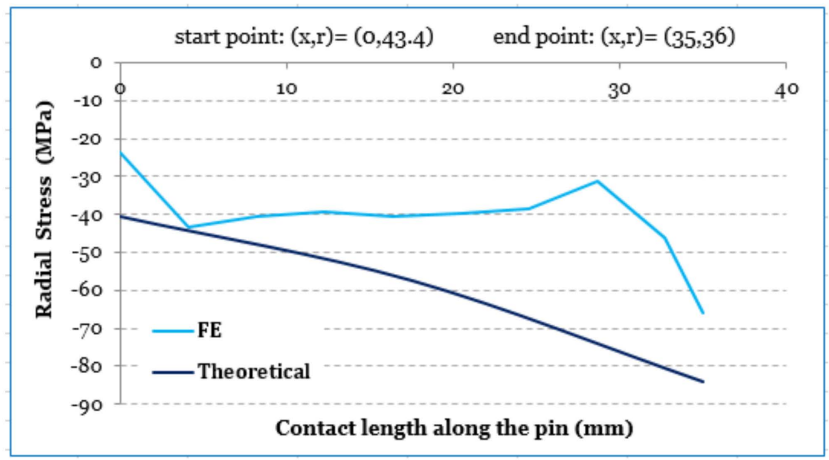

(a)

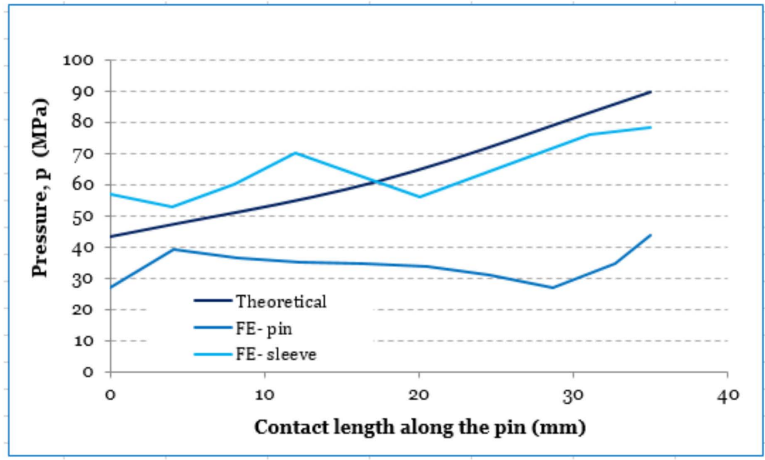

(b)

Figure 11. Stresses in pin along contact length. (a) Comparison of pin radial stress (b) Comparison of contact pressure.

FE results show that the maximum von Mises and Tresca stresses happen at the same point that the maximum stress component in $x$-direction, S11, has occurred and their values are 57.62 $\mathrm{MPa}$ and 66.31 $\mathrm{MPa}$, respectively.

Another parameter of interest to investigate is the contact pressure between pin and sleeve. This pressure in the EPS is transferred to the equipment support. The contact pressure increases from sleeve edge towards its collar. The contact pressure obtained from FE analysis is given in the same graph for both sleeve and pin in Figure 11b. The contact pressure of the sleeve obtained from FE is in good agreement with the graph of theoretical formula from Andrzejuk et al. [15] even though it is not completely uniform and has some dramatic peaks and troughs. It was expected that FE results for both the sleeve and the pin would have the same value, but they are different due to modelling features. Based on the comparison between the theoretical and FE results, it can be concluded that formulas in Andrzejuk et al. [15] are appropriate for prediction of contact pressure of the sleeve-pin as an initial estimation. 


\subsection{Test Boss}

FE results of the test boss are compared with experimental results. The von Mises stress distribution for the test boss produced in post-processing of Abaqus is shown in Figure 12. The magnitude of the maximum von Mises stress in the test boss predicted by FE method is $108 \mathrm{MPa}$. This result is close to the experimental value of $126 \mathrm{MPa}$, which is presented in Table 4. However, there is a difference between positions of the maximum von Mises in the test boss predicted by FEM. Abaqus gives the position of the maximum von Mises stress at angular position of $155^{\circ}$, while based on the experimental measurements, the maximum von Mises has been found to occur at $\pi / 2,5 \pi / 4$ and $7 \pi / 4$ radian. The FE predicted point was not at a position where strain gauges were located during experiments. Therefore, it could be concluded that further experimental research is required to investigate this matter.

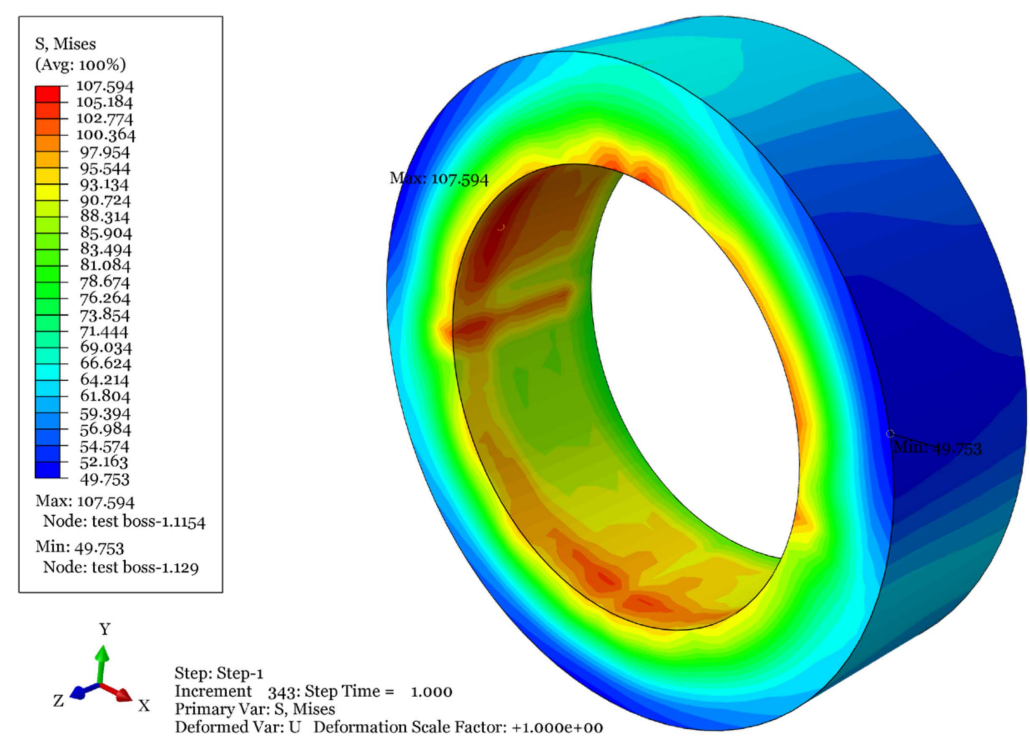

Figure 12. The von Mises stress distribution in the test boss resulted from $200 \mathrm{Nm}$ torque.

In addition, Tresca stress was used as another criterion to compare the stress level for the test boss. The location of the maximum Tresca stress from the FE method is at the same location for the von Mises stress, and its magnitude is $120 \mathrm{MPa}$, which compared with experimental value of $137 \mathrm{MPa}$ (Table 4) could be considered as a close result.

Different stress components in Abaqus for each joint part provide hoop, radial and axial stresses on different planes. In order to extract hoop stress for the test boss, two different cuts were applied. S11 in yz-plane gives the hoop stress in the test boss at $\pi / 2$ and $3 \pi / 2$ positions, while S22 in xz-plane gives the hoop stress at 0 and $\pi$ locations.

Abaqus calculates S11 and S22 in each node and it shows a non-uniform stress distribution along the cross sections on the $\mathrm{xz}$ - and yz-planes with higher values on inner surface of the test boss. To make a comparison with experimental results, only the maximum value on each cross section is considered. The comparison of FE and experimental hoop stress on inner and outer surfaces of the test boss is given in Table 5.

Table 5. Comparison of hoop stress in the test boss on both inner and outer surfaces.

\begin{tabular}{|c|c|c|c|c|c|c|}
\hline \multirow[b]{2}{*}{ Angular Position [rad] } & \multicolumn{3}{|c|}{ Inner Surface } & \multicolumn{3}{|c|}{ Outer Surface } \\
\hline & Experimental [MPa] & FE [MPa] & Error $[\%]$ & Experimental [MPa] & FE [MPa] & Error $[\%]$ \\
\hline 0 & 55.93 & 85.9 & 53.58 & 36.12 & 51.59 & 42.83 \\
\hline$\pi / 2$ & 96.82 & 75.77 & -21.74 & 62.37 & 50.97 & -18.28 \\
\hline$\pi$ & 57 & 84.85 & 48.86 & 36.75 & 49.44 & 34.53 \\
\hline $3 \pi / 2$ & 60.19 & 83.82 & 39.26 & 38.83 & 48 & 23.62 \\
\hline
\end{tabular}


From the comparative results from Table 5, it is observed that accuracy of the FEM to predict the hoop stress has some considerable deviations from experimental values. FEM predictions for the hoop stress on outer surface of the test boss are better than those on the inner surface, but still the errors are significant.

Radial stress is another subject of comparison, whose values from FE analysis are compared with corresponding values from experimental measurements given in Table 6. Compared to the hoop stress, FEM predictions for radial stress are closer to the experimental measurements. Moreover, FEM predicts the position of maximum radial stress correctly, which is at top of the test boss at angular position of $\pi / 2 \mathrm{rad}$ where the complete cut through is located, similar to the test results.

Table 6. Comparison of radial stress in the test boss.

\begin{tabular}{cccc}
\hline & & Inner Surface \\
\hline Angular Position [rad] & Experimental [MPa] & FE [MPa] & Error [\%] \\
\hline 0 & -19.86 & -19.07 & 4.14 \\
$\pi / 2$ & -34.37 & -27.91 & 23.15 \\
$\pi$ & -20.24 & -18.65 & 8.53 \\
$3 \pi / 2$ & -21.37 & -15.84 & 34.91 \\
\hline
\end{tabular}

The axial stress from experimental method can be calculated using Equation (8). Based on the assumption of the friction coefficient $\mu=0.2$, the maximum and minimum experimental axial stresses are $-6.16 \mathrm{MPa}$ and $-10.65 \mathrm{MPa}$, respectively. The FEM prediction gives the axial stress of the test boss ranging between $-22.67 \mathrm{MPa}$ and $+5.5 \mathrm{MPa}$ indicating that both the compressive and tensile stresses occur in the test boss, as shown in Figure 13. Occurrence of tensile stress in some parts of the test boss is due to compressive frictional force in inner side of the test boss which pulls the surrounding materials. This can be considered as one of the advantages of FEM that can capture material behavior locally and it is not restricted to provide only an overall response as the theoretical method does. Most parts of the test boss experience an axial stress in the range from $-4 \mathrm{MPa}$ to $-13 \mathrm{MPa}$, which is close to the range observed from the experimental results.
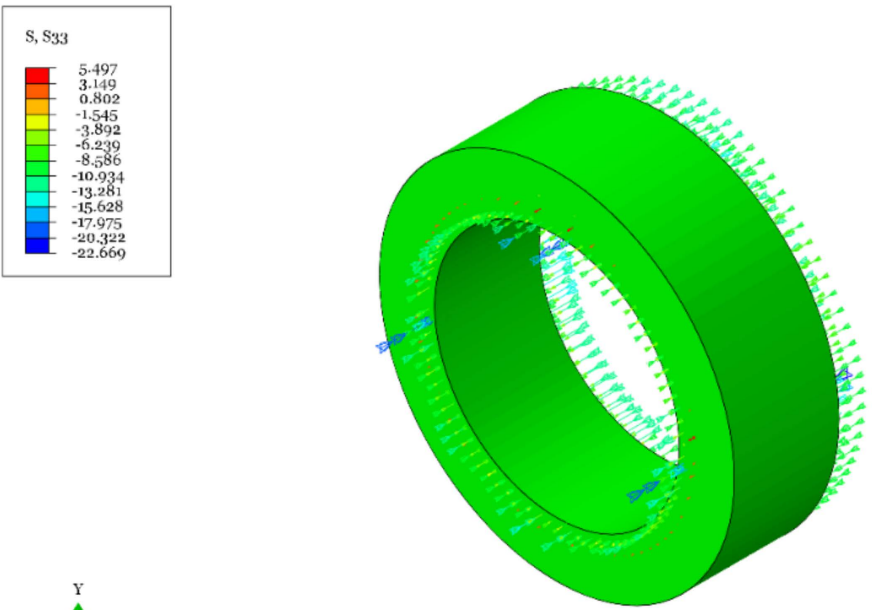

Figure 13. Test boss axial stress resulted from $200 \mathrm{Nm}$ torque.

\section{Conclusions}

In this study, an expanding pin system is analyzed in detail and the stress distribution in the joint system after tightening the fastening screws is clarified. The experimental part of this study, which was performed for three different test layouts namely non-lubricated partly cut sleeve, lubricated partly cut sleeve and lubricated completely cut sleeve, has provided detailed information about stress distribution and its magnitude in the test boss that simulates the equipment support. The experimental results indicate that stress 
concentrations take place in regions near sleeve cut-through and in regions next to it (with $180^{\circ}$ angular distance from sleeve cut-through).

Other findings of the experimental study obtained from non-lubricated partly cut sleeve and lubricated completely cut sleeve are related to dissipation of energy applied to the EPS via torquing. Approximately $71 \%$ of the applied energy dissipates to overcome the friction and to expand the sleeve while only $29 \%$ of the torque is used to expand the test boss. Comparison of the test results of the non-lubricated partly cut sleeve with lubricated partly cut sleeve showed that about $61 \%$ of the loss of energy is due to friction and the rest, which is $39 \%$, is due to elastic expansion of the sleeve. Therefore, it is concluded that around $43 \%$ of the total applied energy to the EPS is lost due to friction in different joint components (including pin, sleeve and test boss) and $28 \%$ is spent to deform the sleeve elastically. The values are valid as long as we assume that friction coefficient in lubricated condition is zero which is an ideal assumption. The elastic deformation, i.e., expansion of the partly cut sleeve results in creation of the clamping force in the EPS. On the other hand, the friction which always behaves as a resisting force has positive effect on producing a better clamping effect since its absence leads to a slack joint which will result in malfunction of the joint system when it is exposed to sudden loads or vibrations.

The FEA results for the sleeve, including radial stress and contact pressure, are very close to the calculated values using formulas of reference [15]. Therefore, it is concluded that those formulas can be used to estimate pin-sleeve contact pressure and radial stress, even though they are derived for a sleeve without any slits. However, the FEA results for pin are not in agreement with the corresponding theoretical formulas. One of the reasons maybe related to mesh size, which can affect results of the FEA considerably and moreover due to discreteness of the contact.

The FEA results for test boss are in good agreement with experimental results. Particularly, the FEA results for von Mises, Tresca and radial stresses are in very good agreement with experimental results and the minor deviations can be attributed to the assumptions and simplifications considered during FE modelling.

Author Contributions: Conceptualization, Ø.K. and H.G.L.; methodology, S.S. and Ø.K.; experimentation, S.S.; software, S.S.; validation, S.S. and Ø.K.; analysis, S.S., Ø.K. and H.G.L.; writing-original draft preparation, S.S.; writing-review and editing, H.G.L. and Ø.K.; supervision, H.G.L. All authors have read and agreed to the published version of the manuscript.

Funding: This research received no external funding.

Institutional Review Board Statement: Not applicable.

Informed Consent Statement: Not applicable.

Data Availability Statement: Not applicable.

Conflicts of Interest: The authors declare no conflict of interest.

\section{References}

1. Karlsen, Ø.; Lemu, H.G. Questionnaire-based survey of experiences with the use of expanding PIN systems in mechanical joints. J. Results Eng. 2021, 9, 100212. [CrossRef]

2. Timoshenko, S.; Goodier, J. Theory of Elasticity; McGraw-Hill: New York, NY, USA, 1951.

3. Eriksson, I. On the bearing strength of bolted graphite/epoxy laminates. J. Compos. Mater. 1990, 24, 1246-1269. [CrossRef]

4. Wang, H.S.; Hung, C.L.; Chang, F.K. Bearing failure of bolted composite joints. Part I: Experimental characterization. J. Compos. Mater. 1996, 30, 1284-1313. [CrossRef]

5. Hung, C.L.; Chang, F.K. Bearing failure of bolted composite joints. Part II: Model and verification. J. Compos. Mater. 1996, 30, 1359-1400. [CrossRef]

6. Yavari, V.; Rajabi, I.; Daneshvar, F.; Kadivar, M.H. On the stress distribution around the hole in mechanically fastened joints. Mech. Res. Commun. 2009, 36, 373-380. [CrossRef]

7. Bozkaya, D.; Müftü, S. Mechanics of the tapered interference fit in dental implants. J. Biomech. 2003, 36, 1649-1658. [CrossRef]

8. Dongliang, Z.; Binwu, W.; Fei, L. The contact stress analysis about the conical expansion sleeve connection. In Proceedings of the Fifth International Conference on Measuring Technology and Mechatronics Automation, Hong Kong, China, 16-17 January 2013. [CrossRef] 
9. Yu, K.; Yang, X. Torque capacity and contact stress analysis of conical interference fit shrink disc of wind turbine. Multidiscip. Modeling Mater. Struct. 2018, 14, 189-199. [CrossRef]

10. Siemiatkowski, Z.; Rucki, M.; Kudlacek, J. Internal Stresses Analysis in the Shrink-Fitted Joints of the Assembled Crankshafts. In Advances in Manufacturing. Lecture Notes in Mechanical Engineering; Hamrol, A., Ciszak, O., Legutko, S., Jurczyk, M., Eds.; Springer: Berlin/Heidelberg, Germany, 2018. [CrossRef]

11. Croccolo, D.; Agostinis, M.D.; Vincenzi, N. Failure analysis of bolted joints: Effect of friction coefficients in torque-preloading relationship. Eng. Fail. Anal. 2011, 18, 364-373. [CrossRef]

12. Nigrelli, V.; Pasta, S. Finite-element simulation of residual stress induced by split-sleeve cold-expansion process of holes. J. Mater. Processing Technol. 2008, 205, 290-296. [CrossRef]

13. Ismonov, S.; Daniewicz, S.R.; Newman, J.C.; Hill, M.R.; Urban, M.R. Three dimensional finite element analysis of a split-sleeve cold expansion process. J. Eng. Mater. Technol. 2009, 131, 31007. [CrossRef]

14. Berkani, I.; Karlsen, Ø.; Lemu, H.G. Experimental and numerical study of Bondura ${ }^{\circledR} 6.6$ PIN joints. IOP Conf. Ser. Mater. Sci. Eng. 2017, 276, 012028. [CrossRef]

15. Andrzejuk, A.; Skup, Z.; Zalewski, R. Analysis of a conical sleeve with pivot joint loading of axial force. J. Theor. Appl. Mech. 2014, 52, 345-358.

16. Langeroodi, S.S. Experimental Study and Optimization of Expanding Pin Technology for Heavy Duty Machine Joint Application. Master's Thesis, University of Stavanger, Stavanger, Norway, 2021. Available online: https://hdl.handle.net/11250/2786185 (accessed on 29 September 2021).

17. Hannah, R.L.; Reed, S.E. Strain Gage Users' Handbook; Chapman \& Hall: London, UK, 1992.

18. Hoffmann, K. Applying the Wheatstone Bridge Circuit; HBM: Darmstadt, Germany, 1974.

19. Zou, Q.; Sun, T.S.; Nassar, S.A.; Barber, G.C.; Gumul, A.K. Effect of lubrication on friction and torque-tension relationship in threaded fasteners. In Proceedings of the International Joint Tribology Conference, San Antonio, TX, USA, 23-25 October 2006; pp. 591-602. [CrossRef]

20. Abaqus 2016 User Manual. Getting Started with Abaqus/CAE, Dassault Systems. 2016. Available online: http://130.149.89.49: 2080/v2016/pdf_books/GET_STARTED.pdf (accessed on 29 September 2021).

21. Forni, D.; Chiaia, B.; Cadoni, E. Strain rate behaviour in tension of S355 steel: Base for progressive collapse analysis. Eng. Struct. 2016, 119, 164-173. [CrossRef]

22. Lee, N.S.; Bathe, K.J. Effects of element distortions on the performance of isoparametric elements. Int. J. Numer. Methods Eng. 1993, 36, 3553-3576. [CrossRef]

23. MITEducation, Eight-Node Brick Element with Reduced Integration (Blog). Available online: https://web.mit.edu/calculix_v2.7 /CalculiX/ccx_2.7/doc/ccx/node27.html\#int1 (accessed on 15 April 2021).

24. Ventsel, E.; Krauthammer, T. Thin Plates and Shells: Theory, Analysis, Applications; Routledge: New York, NY, USA, 2001.

25. Boresi, A.P.; Schmidt, R.J.; Sidebottom, O.M. Advanced Mechanics of Materials, 6th ed.; Wiley: New York, NY, USA, 1985.

26. Hong, Y.; Wang, X.; Wang, Y.; Zhang, Z. Study on reducing the risk of stress corrosion cracking of austenitic stainless steel hydraulically expanded joints. J Eng. Fail. Anal. 2020, 113, 104560. [CrossRef]

27. Al-Chalabi, M.; Huang, C. Stress distribution within circular cylinders in compression. Int. J. Rock Mech. Min. Sci. Geomech. Abstr. 1974, 11, 45-56. [CrossRef]

28. INSTRON. Elastic Hysteresis. Available online: https://www.instron.us/en-us/our-company/library/glossary/e/elastichysteresis\# (accessed on 12 March 2021).

29. Hopkinson, B.; Williams, T.G. The Elastic Hysteresis of Steel. Proc. R. Soc. Lond. Ser. A Contain. Pap. A Math. Phys. Character 1912, 87, 502-511. [CrossRef]

30. Budynas, R.G.; Nisbett, J.K.; Tangchaichit, K. Shigley's Mechanical Engineering Design, 8th ed.; McGraw Hill: New York, NY, USA, 2005. 